\title{
EDITORIAL
}

\section{The Right Thing to Do}

I was recently lecturing at the RSNA when one of my colleagues was asked by an audience member whether he performs (insert quasi-urgent procedure here) on-call. He replied, "Yes I do."

I was surprised. My first thought was, "Really? Why? I don't do that on-call."

He continued, "We do it because it is the right thing to do."

I was about to speak up but then sat in silence after I heard his justification. I had nothing more to say. I was beaten. I concluded that I was a bad person. The words "right thing to do" repeatedly echoed in my head. I recalled that the definition of "right" is correct or good. It is a persuasive word-one that you can't really ignore or argue. It is the moral high ground. I felt like Anakin Skywalker, standing next to a river of flowing lava staring at Obi Wan Kenobi at the end of the 6th (or is it 3rd) Star Wars movie. This was right before he got his legs cut off and he turned into Darth Vader.

"It's over, Anakin! I have the high ground. Do the fistulogram."

I had a bad feeling about this. I didn't need to see the logic behind the argument. Those weren't the droids I was looking for. I continued to think about this after I returned home. But the more I deliberated (rationalized), the more I began to question this line of reasoning. I did a Google search. I learned that this type of argument has a name, "argumentatum ad misericordiam." It is an appeal to the audience's sensibilities, and does not give direct evidence that supports the position or refutes opposing positions. But any counterargument is against the interests of the group the audience claims to support. I began to feel like a lawyer; this didn't help my general feeling of culpability.

Another similar argument that I have made in the past is the "it's-in-the-best-interest-of-our-patients" argument. "We need to increase our clinical presence because it is in the best interest of our patients. Why? "Because it is the right thing to do." Although I do espouse this philosophy, I can't deny that there are costs to this approach, like family, wife, kids, burnout, divorce.
Radiologists, even some interventional ones are constantly criticized for choosing "lifestyle," which is another way to say we're lazy and uncaring. However, as the adage goes, no one ever dies wishing they had spent more time at work.

Recently when I was on-call, I was able to watch my daughter and her Brownie troop sign Christmas carols and hand out cookies at an assisted living complex. I was praying I wouldn't get called in to the hospital. I am not sure who chose the set list but watching a group of 6-year-olds sing, "You're a Mean One Mr. Grinch" to senior citizens bearing a strong resemblance to the title character in the song is a once in a lifetime experience you simply can't get in an IR suite on a Saturday afternoon. When I leave my family at home at night or on a weekend to come to the hospital to handle a true emergency, it is very easy for me to justify this to my daughter. I've even heard her proudly explaining to her little friends, "My daddy has to leave to go to the hospital to help a very sick person." Sadly, some of my call cases don't fall into this category. I can't count the number of times that poor planning on someone else's part constituted an emergency on my part. In these situations, I do the right thing; I come into the hospital to treat the patient. But as I'm driving, I always imagine my daughter saying, "My daddy is leaving us to go to the hospital to appease an incompetent doctor so they won't complain or think he's lazy."

We need a separation of church and state in medicine. We should base decisions on data- not our sense of what may be morally acceptable or not. Unfortunately, there often are large voids in the published medical literature in this regard. I once did a study evaluating referral pattern delays of IVC filters-to date, this is the only one that I have seen that has broached this subject. ${ }^{1}$ We analyzed delays and their impact on patients. I did this because our interventional radiology section adheres to a policy that IVC filters should be placed whenever the indication arises, irrespective of the time of day. After putting in a filter at midnight for a DVT diagnosed at $2 \mathrm{PM}$, I began to
${ }^{1}$ Section of Vascular and Interventional Radiology, University of Chicago Medical Center, Chicago, Illinois.

Address for correspondence and reprint requests: Brian Funaki, M.D., Professor and Section Chief, Section of Vascular and Interventional Radiology, University of Chicago Medical Center, 5840 S. Maryland Avenue, MC 2026, Chicago, IL60637.
Thoracic Interventions; Guest Editor, Charles T. Burke, M.D.

Semin Intervent Radiol 2011;28:1-2. Copyright (C) 2011 by Thieme Medical Publishers, Inc., 333 Seventh Avenue, New York, NY 10001, USA. Tel: +1(212) 584-4662.

DOI: http://dx.doi.org/10.1055/s-0031-1272974.

ISSN 0739-9529. 
suspect that the rest of the hospital did not necessarily adhere to the same guidelines that I did. In fact, we found that the average delay between indication and consultation for filter placement was 1.64 days. Surprisingly, only $2 \%$ of patients suffered documented pulmonary emboli in the interim between diagnosis and filter placement and these occurred after delays of 2 and 8 days. So, the take-home point for me is that although available data do not support nighttime placement of IVC filters, longer delays clearly have morbidity. Because I am not willing to play Russian Roulette with patient welfare, we err on the side of caution and continue to place after-hours filters when requested.

All of us, at one point or another, chose medicine because we wanted to help people. No matter how old, jaded, and cynical we become, that desire never leaves us. Of course we want to help our patients, we try to do the right thing. If there is an objective reason to treat a patient urgently, we should do it. But we need to leave morality out of it. And I don't routinely do fistulograms on Sunday.

$$
\begin{array}{r}
\text { Brian Funaki, M.D. }{ }^{1} \\
\text { Editor-in-Chief }
\end{array}
$$

\section{REFERENCE}

1. Henkle G, Kunz P, Funaki B. Patterns of referral for inferior vena caval filtration: delays and their impact. AJR Am J Roentgenol 2004;183(4):1021-1024 